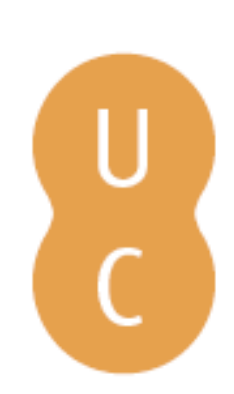

\title{
nombalina
}

\section{O planeamento e gestão das albufeiras de águas públicas de serviço público}

\author{
Autor(es): $\quad$ Almeida, Lara M. Alves de \\ Publicado por: Imprensa da Universidade de Coimbra \\ URL \\ persistente: $\quad$ URI:http://hdl.handle.net/10316.2/31196 \\ DOI: $\quad$ DOI:http://dx.doi.org/10.14195/978-989-26-0244-8_93
}

Accessed : $\quad$ 26-Apr-2023 15:00:10

A navegação consulta e descarregamento dos títulos inseridos nas Bibliotecas Digitais UC Digitalis, UC Pombalina e UC Impactum, pressupõem a aceitação plena e sem reservas dos Termos e Condições de Uso destas Bibliotecas Digitais, disponíveis em https://digitalis.uc.pt/pt-pt/termos.

Conforme exposto nos referidos Termos e Condições de Uso, o descarregamento de títulos de acesso restrito requer uma licença válida de autorização devendo o utilizador aceder ao(s) documento(s) a partir de um endereço de IP da instituição detentora da supramencionada licença.

Ao utilizador é apenas permitido o descarregamento para uso pessoal, pelo que o emprego do(s) título(s) descarregado(s) para outro fim, designadamente comercial, carece de autorização do respetivo autor ou editor da obra.

Na medida em que todas as obras da UC Digitalis se encontram protegidas pelo Código do Direito de Autor e Direitos Conexos e demais legislação aplicável, toda a cópia, parcial ou total, deste documento, nos casos em que é legalmente admitida, deverá conter ou fazer-se acompanhar por este aviso.

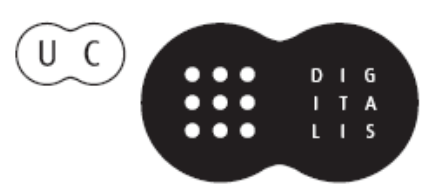




\section{TRUNFOS DE UMA}

\section{EOGRAFIA ACIVA}

\section{DESENVOLVIMENTO LOCAL,}

AMBIENTE,

ORDENAMENTO

E TECNOLOGIA

Norberto Santos

Lúcio Cunha

COORDENAÇÃO 
Lara M. Alves de Almeida

Colaboradora do E-Geo - Centro de Estudos de Geografia e Planeamento Regional, FCSH - UNL

\author{
O PLANEAMENTO E GESTÃO DAS ALBUFEIRAS DE \\ ÁGUAS PÚBLICAS DE SERVIÇO PÚBLICO
}

\title{
1. INTRODUÇÃO
}

Se noutros tempos a garantia de água era tida como uma certeza, actualmente perspectivam-se cenários de escassez que assumem uma dimensão preocupante ${ }^{1}$. Esta realidade, aliada ao uso excessivo resultante dos hábitos consumistas e ao aumento populacional, ocasiona fortes agressôes, que a curto prazo se reflectem na integridade ecológica do meio hídrico².

No caso português, não é apenas a qualidade da água que é necessário assegurar, o armazenamento revela-se uma preocupação e uma necessidade perante o quadro climático actual gerador de incertezas hidrológicas.

Deste novo contexto emerge a necessidade de uma reavaliação das actuais políticas de gestão da água e de assumir uma estratégia, ancorada nesta nova realidade climática (Santos \& Miranda 2006).

A adopçáo de medidas estruturais que contemplem o aproveitamento da água das albufeiras de barragens já existentes constitui uma solução para garantir o abastecimento em épocas de escassez hídrica. Aliás, saliente-se que o benefício em aproveitar estas reservas de água foi uma das medidas implementadas para mitigar as variaçóes sazonais e anuais decorrentes da seca vivida no ano de 2005.

Considerando o modelo de abastecimento implementado em Portugal, aplicando o princípio da precaução e integridade da substância água, é desejável que as albufeiras classificadas de protegidas sejam assumidas como destinadas ao abastecimento público, acautelando-se a boa qualidade destas massas de água com vista ao seu consumo público, pois só assim faz sentido que sejam declaradas reservatórios estratégicos.

Em face do interesse que as albufeiras de águas públicas representam no quadro do abastecimento público, e sabendo que a sua gestão e preservação dependem da execução de PEOT (Planos Especiais de Ordenamento do Território), concretamente pela realização de

\footnotetext{
${ }^{1}$ Mais de $1 / 3$ da população do mundo vive com carências de água e estima-se que no ano de 2050, 4 bilióes de pessoas (total da população 8,9 biliôes) vivam em países com graves problemas de escassez de água potável (Clarke \& King, 2004).

${ }_{2}$ "As reduçôes das terras aráveis, a generalizada escassez de água, a diminuição das existências de alimentos e de peixes, o aumento das cheias e das secas prolongadas são fenómenos que ocorrem já em muitas partes do mundo. As alteraçōes climáticas modificarão os padrōes de pluviosidade e reduzirão ainda mais a água potável disponível, de 20 a 30\% em determinadas regióes» (Comissão Europeia 2008).
} 
Planos de Ordenamento de Albufeiras de Águas Públicas (POAAP), afigura-se pertinente reflectir sobre o desempenho destes instrumentos, não esquecendo as implicaçóes que advêm das alteraçóes previstas no novo diploma legal, publicado em Maio de 2009, e perceber em que medida poderão contribuir para uma nova geração de POAAP.

\section{A Gestão das Albufeiras de Águas Públicas e o Ordenamento do TerRitório}

Enquanto a gestâo da água compreende a protecção, recuperação e a melhoria do estado das águas e dos ecossistemas associados, abrangendo o seu planeamento e a protecçáo de pessoas e bens contra situaçóes extremas, gestáo dos usos incluindo os serviços de tratamento, captação e distribuição (MAOTDR 2008), o ordenamento do território deve assegurar a salvaguarda dos valores naturais essenciais, garantindo, entre outros objectivos, que os recursos hídricos e outros locais com interesse particular para a conservação da natureza constituam objecto de protecção compatíveis com a normal fruição pelas populaçóes das suas potencialidades específicas, de acordo com a Lei n. ${ }^{\circ}$ 48/98 de 11 de Agosto.

Em face deste articulado, e em termos genéricos, reconhece-se uma complementaridade de políticas no quadro da sustentabilidade ambiental e consequente preservação dos recursos hídricos, que se traduzem em instrumentos e medidas, cuja articulação requer um esforço de integração e coordenação (MAOTDR 2008). Contudo, essa articulação nem sempre se revela possível dada a discordância temporal, uma vez que não há garantia que quando um Instrumento de Gestáo Territorial (IGT) de hierarquia inferior é aprovado, este recolha orientaçóes dos instrumentos de ordem superior, em virtude destes ainda não existirem.

A falta de orientaçóes supra-municipais, decorrentes da ausência de IGT, é uma constatação nos POAAP aprovados.

\subsection{Os POAAP e os PMOT}

No âmbito da gestão das albufeiras são os POAAP que assumem o papel central no quadro da gestão e ordenamento destes territórios. Entre outros objectivos têm a responsabilidade de equacionar a coexistência de diversas actividades na sua área de intervenção, regulamentando os usos sem prejuízo das utilizaçóes principais, para as quais as albufeiras estão destinadas, estabelecendo regras para as actividades secundárias ${ }^{3}$ do plano de água não comprometendo os fins principais que estiveram subjacentes na construção da barragem sem esquecer que o abastecimento doméstico tem prioridade sobre as restantes utilizações ${ }^{4}$.

No caso dos PMOT (Planos Municipais de Ordenamento do Território), reconhece-se que encaram as questóes relativas à água como uma condicionante ao desenvolvimento, sendo raro nas propostas de ordenamento dos PDM (Planos Directores Municipais), nomeadamente os de primeira geraçáo, a existência de uma visão estratégica de conservação dos

\footnotetext{
${ }^{3}$ Entende-se como actividade secundária as actividades distintas dos usos principais, passíveis de serem desenvolvidas na albufeira, nomeadamente a pesca, a prática balnear, a navegaçáo recreativa, as actividades marítimo-turísticas e a realização de competiçóes desportivas, cfr. alínea a) do artigo 3o do DL n.o 107/2009 de 15 de Maio.

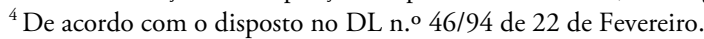


recursos, mesmo porque estes não tiveram a oportunidade de considerarem as orientaçóes decorrentes dos Planos de Bacia Hidrográfica (PBH) ${ }^{5}$ (MAOTDR 2008).

Quanto ao regime jurídico dos PMOT e dos POAAP, estes partilham o mesmo quadro legal, na medida em que possuem natureza regulamentar e determinam a fixação de parametros concretos de uso do solo. Tal como os PMOT também os POAAP têm carácter vinculativo para entidades públicas e para os particulares. Contudo, e quanto à fixação de regras de ocupação, uso e transformação dos solos cabe aos PMOT e não aos POAAP a tarefa de classificar e qualificar os mesmos. Aos POAAP fica reservado o estabelecimento de regimes que visem a salvaguarda dos recursos naturais de interesse nacional (Oliveira 2006).

Não obstante o quadro legal existente acontece, por vezes, que os regimes estabelecidos nos POAAP conflituam com as regras de ocupaçáo determinadas em sede de PDM, ou seja, a transposição das orientaçóes para os PMOT nem sempre se verificam e as conflitualidades são uma realidade na articulação entre estes IGT. Os municípios iniciam procedimentos de revisão dos seus PMOT para adaptação às disposiçôes superiores, que são morosos levando a situaçáo de discrepância, que podem prolongar-se durante anos. Por outro lado, com a publicação de legislação cada vez mais restritiva, nomeadamente no domínio hídrico, agrava-se a potencial conflitualidade entre as disposiçóes entre IGT.

\subsection{Os POAAP em território continental}

No contexto nacional, nem todas as albufeiras ${ }^{6}$ estão abrangidas por POAAP. Existem apenas 33 planos publicados, sendo que alguns correspondem a mais do que uma albufeira, como se verifica pelo Quadro 1.

Quadro 1 - Planos de Ordenamento de Albufeiras em vigor (Setembro 2009)

\begin{tabular}{l|c|l|l|c}
\hline NOME DO POAAP & $\begin{array}{c}\text { ESTUDO } \\
\text { DA SECA }\end{array}$ & CLASSIFICAÇÃO & $\begin{array}{c}\text { BACIA } \\
\text { HIDROGRÁFICA }\end{array}$ & $\begin{array}{c}\text { ANO } \\
\text { APROVAÇĀO }\end{array}$ \\
\hline Alqueva e Pedrógáo & $\bullet$ & Protegida & Rio Guadiana & 2006 \\
\hline Aguieira & $\bullet$ & Protegida & Rio Mondego & 2007 \\
\hline Apartadura & $\bullet$ & Protegida & Rio Tejo & 2003 \\
\hline Alto Lindoso e Touvedo & $\bullet$ & Protegida & Rio Lima & 2004 \\
\hline Alvito & $\bullet$ & Protegida & Rio Sado & 1998 \\
\hline Azibo & $\bullet$ & Protegida & Rio Douro & 1993 \\
\hline Bravura & $\bullet$ & Protegida & Rib. do Algarve & 2004 \\
\hline Cabril, Bouçã e Sta. Luzia & $\bullet$ & Protegida & Rio Zêzere & 2002 \\
\hline Caia & $\bullet$ & Protegida & Rio Guadiana & 1993 \\
\hline Campilhas & $\bullet$ & Utiliz. Livre $\psi$ & Rio Sado & 2007 \\
\hline
\end{tabular}

${ }^{5}$ Com a publicação do DL n. ${ }^{6} 69 / 90$ de 2 de Março é regulada a elaboração, aprovação e ratificação dos PMOT, traduzindo-se, após esta data, numa maior publicação dos PDM, enquanto que os primeiros POAAP entraram em vigor em 1993 - Caia, Azibo e Castelo do Bode, atingindo maior expressão a partir do ano 2002, momento em que as estratégias apontadas pelos instrumentos de ordem nacional nesta matéria já eram conhecidas (os Planos de Bacia Hidrográfica são aprovados entre 2001 e 2002 e o Plano Nacional da Água publicado em 2002).

${ }^{6}$ De acordo com a Portaria n. ${ }^{\circ}$ 522/2009 de 15 de Maio existem 167 albufeiras de águas públicas de serviço público em território continental. 


\begin{tabular}{|c|c|c|c|c|}
\hline NOME DO POAAP & $\begin{array}{l}\text { ESTUDO } \\
\text { DA SECA }\end{array}$ & CLASSIFICAÇĀO & $\begin{array}{c}\text { BACIA } \\
\text { HIDROGRÁFICA }\end{array}$ & $\begin{array}{c}\text { ANO } \\
\text { APROVAÇĀO }\end{array}$ \\
\hline Crestuma-Lever & & Protegida $\psi$ & Rio Douro & 2007 \\
\hline Caniçada & & Protegida & Rio Cavado & 2002 \\
\hline Castelo do Bode & 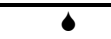 & Protegida & Rio Zêzere & 2003 \\
\hline Cova do Viriato & & Protegida & Rio Tejo & 2004 \\
\hline Enxoé & 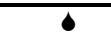 & Protegida & Rio Guadiana & 2006 \\
\hline Divor & $\bullet$ & Protegida & Rio Tejo & 2005 \\
\hline Fonte Serne & $\bullet$ & Utiliz. Livre $\psi$ & Rio Sado & 2007 \\
\hline Funcho e Arade & $\bullet$ & Protegida & Rib. do Algarve & 2008 \\
\hline Fronhas & & Protegida & Rio Mondego & 2009 \\
\hline Gameiro & & Condicionada & Rio Tejo & 1993 \\
\hline Idanha & $\bullet$ & Protegida & Rio Tejo & 2008 \\
\hline Magos & $\checkmark$ & Utiliz. Livre $\psi$ & Rio Tejo & - \\
\hline Maranhão & 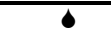 & Protegida & Rio Tejo & 1999 \\
\hline Montargil & $\bullet$ & Utiliz. Livre $\psi$ & Rio Tejo & 2002 \\
\hline Monte Novo & $\bullet$ & Protegida & Rio Guadiana & 2003 \\
\hline Monte da Rocha & $\bullet$ & Protegida & Rio Sado & 2003 \\
\hline Odivelas & $\bullet$ & Utiliz. Livre $\psi$ & Rio Sado & 2007 \\
\hline Pego do Altar & $\bullet$ & Utiliz. Livre $\psi$ & Rio Sado & 2005 \\
\hline Póvoa e Meadas & $\bullet$ & Protegida $\psi$ & Rio Tejo & 1998 \\
\hline Régua e Carrapatelo & & Protegida $\psi$ & Rio Douro & 2002 \\
\hline Santa Águeda e Pisco & & Protegida & Rio Tejo & 2005 \\
\hline Santa Clara & $\bullet$ & Protegida $\psi$ & Rio Mira & 2007 \\
\hline São Domingos & $\bullet$ & Protegida & Rib. do Oeste & 2009 \\
\hline Tapada Grande & & Protegida & Rio Guadiana & 2005 \\
\hline Tapada Pequena & & Utiliz. Livre & Rio Guadiana & 2008 \\
\hline Vale de Gaio & $\bullet$ & Utiliz. Livre $\psi$ & Rio Sado & 2008 \\
\hline Vigia & $\bullet$ & Protegida & Rio Guadiana & 1998 \\
\hline Vilar & & Protegida & Rio Távora & 2004 \\
\hline
\end{tabular}

Albufeiras sujeitas ao acompanhamento da comissão para a seca 2005, com POAAP em vigor. $\Psi$ Albufeiras sujeitas reclassificadas no quadro do novo regime, cfr. Portaria n. ${ }^{\circ}$ 522/2009 de 15 de Maio

Fonte: Adaptado de Alves de Almeida 2009

Atendendo apenas às albufeiras com POAAP aprovado constata-se que a água armazenada destina-se maioritariamente à produção de energia, ao abastecimento público e à rega. Contudo, existem outras utilizaçóes, que mesmo pouco comuns (defesa contra as cheias, valorização da paisagem, recreio e navegação), também são relevantes e actuam paralelamente com os fins anteriormente referidos.

Da leitura do Quadro 1 confirma-se que a maioria das albufeiras são protegidas ${ }^{7}$ representando $32 \%$ do total de albufeiras de águas públicas de serviço público, com esta classificação, no actual quadro legal e afectas a POAAP em vigor.

${ }^{7}$ As Albufeiras Protegidas são aquelas que se destinam ao abastecimento público ou se prevê virem a ser utilizadas para esse fim e aquelas onde a conservação dos valores naturais determina a sua sujeição a um regime de protecção mais elevado, designadamente as que se encontram inseridas em áreas classificadas, tal como definidas na Lei da Água, cfr. alínea b) do ponto 2 do artigo 7a do DL n. ${ }^{o} 107 / 2009$ de 15 de Maio. 
Ainda quanto à classificação não se pode ser alheio ao facto do actual quadro legal ter reclassificado algumas albufeiras, mesmo aquelas que já tinham POAAP, entre as quais Crestuma-Lever, no Rio Douro, cuja classificação transitou de utilização livre para protegida. Uma vez que esta albufeira é a principal origem de água para o conjunto da área metropolitana do Porto, esta reclassificação veio conciliar aquele que é o uso predominante da água com a sua classificação.

Como as albufeiras são dos primeiros recursos a serem tomados pelas entidades gestoras das águas públicas em caso de escassez hídrica, a sua qualidade deverá constituir uma preocupaçáo. Atendendo a esta realidade, e a propósito da seca declarada em 2005, a Comissão de Gestão de Albufeiras determinou quais os reservatórios considerados estratégicos em épocas de seca rigorosa ${ }^{8}$, ou seja, aqueles que se prevê que possam garantir os abastecimentos às populaçóes e que justificam o seu estatuto de albufeiras protegidas, embora não sejam regularmente utilizadas para este propósito. A título de exemplo, destacase o Azibo que abastece Bragança, o Caia que abastece Elvas e Campo Maior, a Bravura responsável pelo abastecimento do concelho de Lagos e Portimão, o Alvito que fornece água a 37.500 habitantes (às populaçôes de Alvito, Portel, Cuba, Vidigueira e Viana do Alentejo) e Castelo do Bode considerado como a principal origem de água à regiáo de Lisboa, abastecendo 2.200.000 habitantes.

Perante estas circunstâncias, considera-se essencial que as entidades competentes nesta matéria assumam que as albufeiras protegidas, nomeadamente aquelas que foram identificadas no estudo da seca, são estratégicas ao abastecimento. Como tal, deverá ser imperativo a garantia da qualidade da sua água, porque só a boa qualidade das massas de água assegurará o abastecimento das populaçóes com água potável.

\section{Aspectos releVantes do novo Regime Jurídico de ProtecÇão das Albufeiras DE ÁGuas Públicas de SERVIÇO Público}

A Lei da Água, publicada em finais de 2005, e o regime jurídico da utilização dos recursos hídricos, em conjunto com a lei da titularidade dos mesmos instituíram um novo quadro de proteç̧âo legal dos recursos hídricos em Portugal. A necessidade de adaptar, a este novo quadro legal, o regime de protecção das albufeiras de águas públicas de serviço público, aliada à circunstância deste se encontrar disperso por vários diplomas, alguns já desadequados em face da legislação publicada, levou à revogação da antiga legislação e à compilação de toda a matéria num único diploma (DL n. ${ }^{\circ} 107 / 2009$ de 15 de Maio).

A primeira novidade do actual diploma reside na compilação num único documento do regime de protecção das albufeiras, lagos e lagoas, dando cumprimento à regulamentação da Lei da Água.

A publicação do actual regime jurídico determina o carácter obrigatório da classificação das albufeiras de águas públicas, estando sujeita aos seguintes tipos': utilização protegida, utilização condicionada e utilização livre. Esta alteraçáo de tipologias fez com que houvesse

\footnotetext{
$870 \%$ das albufeiras consideradas como estratégicas, segundo a Comissão de Gestão de Albufeiras, estão abrangidas por POAAP - assinaladas no Quadro 1.

${ }^{9}$ As tipologias foram designadas em 1988 com a publicação do Decreto Regulamentar n.o 2/88 de 20 de Janeiro, onde estavam previstas quatro classificaçôes, as actuais e a utilizaçâo limitada, que agora foi anulada.
} 
necessidade de reclassificar as albufeiras, principalmente aquelas que estavam designadas como utilização limitada e que agora recebem uma nova classificação. Algumas destas reclassificaçóes aconteceram em albufeiras com POAAP aprovado, mais concretamente em onze, como se pode constatar pela leitura do Quadro 1.

A actual legislação concretiza, quanto à dimensão espacial da zona terrestre de protecção, um aumento da área de protecção que pode ser ajustada até uma largura máxima de $1.000 \mathrm{~m}$, para os casos em que seja elaborado um PEOT, integrando a zona reservada de $100 \mathrm{~m}$.

A possibilidade em aumentar a zona terrestre de protecção é por si só um ganho face à legislaçáo anterior, onde a elaboraçáo do plano estava circunscrito a uma faixa de $500 \mathrm{~m}$ não variável. Contudo, acreditamos que perdeu-se a oportunidade de possibilitar alguma flexibilidade na definição da zona de protecção, e esta ser adaptada em função das características de cada território, permitindo assim, que o modelo de ocupação do solo e o cumprimento dos objectivos ambientais sejam equacionados em função das características e das necessidades de cada área de intervenção e não impostos por uma faixa com uma determinada largura, medida na horizontal a partir da linha de pleno armazenamento que, em certos casos, não garante a protecção da massa de água porque está desajustada às especificidades biofísicas da albufeira e área envolvente.

Uma vez que o conceito de gestão por bacia hidrográfica é reconhecido ao nível regional, considera-se que no âmbito das albufeiras a totalidade da bacia hidrográfica deve constituir o ponto de partida para a gestão e planeamento destes territórios. Desta forma, acredita-se que os futuros $\mathrm{PBH}$ podem contribuir para uma harmonização de políticas e estratégias com vista a uma gestão integrada da água para estes territórios.

Em face da hierarquia de IGT que o quadro legal prevê, não há necessidade de criar uma nova figura, mas sim operacionalizar o articulado existente. Assim, e ponderando que estão em elaboração PDM de segunda geração, bem com IGT de ordem superior, deverão as entidades competentes, através dos seus representantes nas comissóes de acompanhamento dos PDM, garantir que as indicaçóes dos planos supra-municipais em elaboração sejam transpostas para a escala local.

Uma vez que, no âmbito da elaboração e revisão dos POAAP e dos PDM está previsto a presença das Administraçóes de Região Hidrográfica (ARH), criadas em 2002, nas comissóes de acompanhamento destes instrumentos, considera-se que estão reunidas as condiçóes para uma correcta concertação de interesses entre planos.

Quanto ao regime de utilização instituído no actual diploma subsistem algumas dúvidas, na medida em que a descriminação das actividades interditas e condicionadas para as albufeiras e zonas terrestres são aplicadas a todas as albufeiras, não havendo qualquer diferença quanto à sua classificação, ou seja, o diploma não diferencia as actividades consoante se as albufeiras são de utilizaçáo protegida, condicionada ou livre, o que à partida suscita algumas dúvidas quanto à opçáo tomada pelo legislador, na medida em que as albufeiras de utilizaçáo protegida destinam-se ao abastecimento público e como tal, era esperado que os condicionalismos no plano de água e zona de protecçáo terrestre fossem mais restritivos, sobretudo aos usos potencialmente poluidores como são exemplo as actividades marítimo-turísticas e a navegação de recreio.

Ainda de acordo com o novo diploma fica estipulado que nos perímetros urbanos definidos em sede de PMOT, e que se localizem na área afecta a POAAP, continuam-se a aplicar as regras constantes nos PMOT, não sendo contudo permitida a ampliação e a 
criação de novos perímetros. Esta disposição atribui aos PMOT a responsabilidade de estabelecerem as regras de ocupação do solo nestes territórios sensíveis, não obstante destes o executarem mediante orientaçóes estabelecidas nos POAAP, constituindo esta opção um desafio determinante em matéria de concertação entre estes dois níveis de IGT.

Uma vez que ainda não foram publicados POAAP após a entrada em vigor deste novo quadro legal, aguarda-se com algum interesse as futuras aprovaçóes principalmente no que respeita à componente de caracterização da área de intervenção, que agora vem regulada através de normas técnicas. Esta obrigatoriedade determina que certos elementos sejam actualizados, uma vez que a maioria dos levantamentos e caracterizaçóes eram decorrentes dos PBH e do Plano Nacional da Água (PNA) e por isso carentes de actualização.

O caminho que agora se perspectiva passa pela aposta na articulação entre planos, pelo que as disposições que constarem nos futuros Planos de Gestão da Bacia Hidrográfica (PGBH) e nos Planos Específicos de Gestão das Águas (PEGA) devem ser transpostas para os novos POAAP e PMOT de segunda geração, garantindo a articulação entre os IGT.

\section{CONSIDERAÇÓES FINAIS}

Para além da questão jurídica subjacente à gestão dos recursos hídricos, há que ter em conta quer o actual cenário de variaçáo do clima, quer a irregularidade resultante da forte variação temporal e espacial da precipitação e, também, a nossa dependência de Espanha de onde provém «cerca de 40\% do total de águas superficiais disponiveis» (Oliveira 2005).

Desta forma, emerge a necessidade de adopção de políticas que imponham a racionalização do uso da água, assim como medidas estruturais que contemplem o aproveitamento da água das albufeiras de águas públicas de serviço público, assumindo estes territórios como estratégicos ao abastecimento público.

Embora existam diversos IGT que determinam normas para as albufeiras e áreas de protecção, concretamente sobre a salvaguarda destes ecossistemas, fazem-no com o intuito estratégico e sem competências regulamentares. No âmbito da gestão das albufeiras de águas públicas, são os POAAP os instrumentos de gestáo territorial, que assumem o papel central no quadro da sua gestão e ordenamento, partilhando esta missão com os PMOT, também estes com carácter vinculativo. A estes instrumentos, compete a definiçâo das regras e regimes de salvaguarda e de gestão, compatíveis com a utilização sustentável destes territórios.

A entrada em vigor da nova legislação permitiu a compilação de toda a matéria que regulamenta as albufeiras num único diploma, e incorpora também nesta legislação os lagos e as lagoas, dando cumprimento à regulamentação da Lei da Água.

Como alteraçóes face à legislaçáo anterior destaca-se a possibilidade de aumentar a zona terrestre de protecção e a determinação de regras para todas as albufeiras, mesmo que estas não estejam abrangidas por POAAP.

Espera-se que no âmbito das competências das novas ARH, e em conformidade com as atribuiçóes que lhes foram concedidas, para a elaboração dos PGBH e dos PEGA, conjugada com as revisóes dos PDM, que estão a decorrer por todo o país, seja possível reforçar a articulação dos IGT actualmente em elaboração com os planos sectoriais em vigor e dissipar o desfasamento temporal que se tem vindo a verificar entre a aprovação dos instrumentos de carácter estratégico e os de nível local. 
Desta forma, deposita-se grande esperança nos novos PGBH, que perspectiva-se estejam concluídos em breve, e que para além dos objectivos que lhe estáo associados possam identificar as albufeiras de águas públicas de serviço público e respectiva bacia hidrográfica como áreas potencialmente vulneráveis, impondo para estes territórios intervençóes e procedimentos específicos, nomeadamente através da indicação expressa das regras, usos e actividades que interferem com o estado ecológico das albufeiras, a serem introduzidas nos IGT de carácter regulamentar, como os POAAP e os PMOT, de modo a garantir a utilização sustentável das águas e a sua protecção.

\section{REFERÊNCIAS BIBLIOGRÁFICAS}

Alves de Almeida, L. 2009, O Planeamento e Gestão da Albufeira de Castelo do Bode. Uma Reflexão sobre os Planos de Ordenamento de Albufeiras de Águas Públicas, Dissertação de Mestrado em Gestão do Território, Faculdade de Ciências Sociais e Humanas da Universidade Nova de Lisboa, Lisboa.

Comissão Europeia 2008, Alteraçōes Climáticas e Segurança Internacional, Conselho da Comissão Europeia, Bruxelas.

Comissão para a Seca 2005, Relatório de Balanço. Seca 2005, Comissão de Gestão de Albufeiras.

Clarke, Robin \& King, Jannet 2004, The Atlas of Water. Mapping the world's most critical resource, Earthscan, Myriad Editions Limited, London.

INAG 2002, Plano Nacional da Água, Volumes I e II, Instituto da Água, Ministério do Ambiente e Ordenamento do Território, Lisboa.

MAOTDR 2008, Articulação entre a Gestão da Água e o Ordenamento do Território, $1^{a}$ Edição, Ministério do Ordenamento e do Desenvolvimento Regional, Lisboa.

Oliveira, Fernanda Paula 2007 'Planos especiais de ordenamento do território: tipicidade e estado da arte', RevCEDOUA - Revista do Centro de estudos do Direito do Ordenamento, do Urbanismo e do Ambiente, n.o 17 Ano IX pp.71-81.

Oliveira, J. Santos 2005, 'Bases de uma Gestão Ambiental Correcta de Recursos Hídricos em Portugal', Recursos Hidricos - APRH, vol. 16, n. ${ }^{\circ} 13$, pp. 5-12

Santos \& Miranda (eds) 2006, Alterações Climáticas em Portugal. Cenários, Impactos e Medidas de Adaptação, Projecto SIAM II, Gradiva, Lisboa. 